\title{
ZmMATE6 From Maize Encodes a Citrate Transporter That Enhances Aluminum Tolerance in Transgenic Arabidopsis Thaliana
}

\section{Hanmei Du}

Sichuan Agricultural University

\section{Peter Ryan}

Commonwealth Scientific and Industrial Research Organisation

Chan Liu

Sichuan Agricultural University

Hongjie Li

Sichuan Agricultural University

\section{Wanpeng Hu}

Sichuan Agricultural University

\section{Weina Yan}

Sichuan Agricultural University

\section{Ying Huang}

Sichuan Agricultural University

\section{Wenzhu He}

Sichuan Academy of Agricultural Sciences

\section{Bowen Luo}

Sichuan Agricultural University

\section{Xiao Zhang}

Sichuan Agricultural University

\section{Shibin Gao}

Sichuan Agricultural University

\section{Shufeng Zhou}

Sichuan Agricultural University

\section{Suzhi Zhang ( $\nabla$ suzhi1026@163.com)}

Key Laboratory of Biology and Genetic Improvement of Maize in Southwest China of Agricultural Department, Ministry of Agriculture, Maize Research Institute, Sichuan Agricultural University, Wenjiang 611130, China

\section{Research Article}

Keywords: Al toxicity, ZmMATE6, maize, overexpression, citrate, Arabidopsis thaliana

Posted Date: January 22nd, 2021

DOI: https://doi.org/10.21203/rs.3.rs-141756/v1

License: (c) (i) This work is licensed under a Creative Commons Attribution 4.0 International License. Read Full License 
Version of Record: A version of this preprint was published at Plant Science on October 1st, 2021. See the published version at https://doi.org/10.1016/j.plantsci.2021.111016. 


\section{Abstract}

Background: The yields of cereal crops grown on acidic soils are often reduced by aluminum (Al) toxicity because the prevalence of toxic $\mathrm{Al}^{3+}$ cations increases as $\mathrm{pH}$ falls below 5.0. The Al-activated release from the roots of simple organic acids such as malate and citrate confers resistance to Al in a many plant species including maize (Zea mays L.). The Aldependent release of citrate from resistant lines of maize is controlled by ZmMATE1 which encodes a multidrug and toxic compound extrusion (MATE) transporter protein. ZmMATE1 resides on chromosome 6 and its expression in roots is induced up to four-fold by Al treatment. ZmMATE6 is another member of this family in maize whose expression is also increased by Al treatment. We investigated the function of this gene in more detail to determine whether it also contributes to $\mathrm{Al}$ resistance.

Results: Quantitative RT-PCR measurements found that in the absence of Al ZmMATE6 was expressed in the roots and leaves of Al-resistant and sensitive in-bred lines, and that expression levels in the root tips were lower than in the rest of the root tissue. Treatment with Al induced ZmMATE6 expression in all tissues but several other divalent or trivalent cations tested had no effect on expression. This expression pattern and the induction by Al treatment was confirmed in Arabidopsis lines transformed with $\beta$-glucuronidase where the ZmMATE6 promoter was used to drive expression. While subcellular localization of the ZmMATE6 protein could not be determined with confidence transgenic Arabidopsis lines expressing ZmMATE6 displayed a greater Al-activated release of citrate from the roots and were significantly more resistant to Al toxicity than controls. This was associated with reduced accumulation of Al in the root tissues.

Conclusions: Our results demonstrated that ZmMATE6 expression is induced by Al and functions as a citrate transporter. While some findings are consistent with ZmMATE6 contributing to Al resistance in maize, further research is required to confirm this result.

\section{Background}

Approximately $30 \%$ of arable soil and $50 \%$ of the potential farmland globally has a pH of 5.0 or less [1]. These acid soils present many challenges to crop growth but the most important is aluminum (Al) stress. The highly toxic $\mathrm{Al}^{3+}$ cations becomes more prevalent in the soil solution at low pH and can inhibit root elongation at low concentrations [2-4]. Smaller root systems reduce the uptake of water and nutrients and increase the risk of lodging which comprise yields [5, 6].

Some plant species and even genotypes within species are able to resist Al stress better than others. Many mechanisms have been proposed to account for this resistance including those that exclude Al from the root tissues and others that sequester or otherwise detoxify any $\mathrm{Al}$ that is taken up by the roots [7, 8]. An important mechanism of Al exclusion that occurs in a wide range of species relies on the release of low molecular weight organic anions from the roots, especially malate and citrate [9-12]. The Al-dependent release of these anions protects the roots, and especially the root tips, by binding with the $\mathrm{Al}^{3+}$ cations in the apoplast to form complexes that are less harmful and less easily absorbed by the roots $[13,14]$. The Al-dependent release of organic anions from roots can be divided into two types of responses depending on how rapidly after the release begins to occur after $\mathrm{Al}$ is added. In some species the release is rapid (Type I pattern) because Al interacts with transporter proteins in the plasma membrane of the root cells that are expressed constitutively. In other species, organic anion release increases gradually over several hours (Type II pattern) because Al first induces the expression of the genes and proteins encoding the transporters. Type I responses have been described in wheat (Triticum aestivum L.) [14], buckwheat (Fygopyrum esculentum Moench) [15] and rape (Brassica napus) [16] while Type II responses have been described in rye (Secale cereale L.) [17], Arabidopsis [18], rice bean (Vigna umbellata) [19] and common bean [20]. Since these two responses are independent processes they can occur together. For instance, rye displays a Type I pattern for malate release and a Type II pattern for citrate release [17, 21].

Page $3 / 22$ 
The Al-dependent release of malate is controlled by members of the aluminum-activated malate transporter (ALMT) gene family which encode anion channels in the plasma membrane of root cells [22]. While ALMTs have been shown to contribute to Al resistance in a wide range of species $[11,23]$ most members of this family perform other functions unrelated to Al resistance [24]. The Al-dependent release of citrate, by contrast, is mediated by members of the multidrug and toxic compound extrusion (MATE) family of transporter proteins. This family is widely distributed in prokaryotes and eukaryotes [25] and forms a very large family in plants. MATEs transport a diverse range of compounds and function in the export of secondary metabolites and toxins, development, nutrition and stress responses [26-29] .The SbMATE transporter from sorghum (Sorghum bicolor L.) and HvAACT1 (HvMATE) transporter from barley (Hordeum vulgare L.) were the first MATEs linked with Al resistance [30-32], but others perform similar roles in many other species [19, 3340].

Al tolerance in maize (Zea mays L.) is a quantitative trait [41-43] with at least five QTLs on chromosomes 2, 6 and 8 in one biparental population examined [44]. The ZmMATE1 gene co-locates with a resistance QTL on chromosome 6 and explains $16 \%$ of the phenotypic variation in resistance [33]. ZmMATE1 encodes plasma membrane-localized protein that mediates the Al-dependent release of citrate from cells and shares significant amino acid identity with SbMATE (52\%) from sorghum and AtMATE (64\%) from Arabidopsis [33]. ZmMATE1 expression was induced by Al, particularly in the root tips, and Al-tolerant lines show a greater increase in expression than Al-sensitive lines due to a higher copy number of the ZmMATE1 gene [45].

The maize genome contains 49 MATE genes which separate into seven phylogenetic categories (I-VII) [46]. Only a few of these genes have been examined in detail but researchers have performed transcript analyses and showed that the expression of several MATE genes, in addition to ZmMATE1, was responsiveness to Al treatment [46]. Among these responsive genes ZmMATE6 (GRMZM2G080450) (denoted as ZmMATE23 in Zhu et al [46]) was rapidly induced by three-fold following Al treatment. This study provides the first functional analysis of ZmMATE6 and begins to investigate whether it could also be contributing to Al resistance in maize in the same way as ZmMATE1.

\section{Results}

\section{Cloning and molecular characteristics of the ZmMATE6 sequence}

The complete coding sequences of ZmMATE6 was amplified and sequenced from the Al-resistant inbred line 178 using gene-specific PCR primers (Fig. S1). The gene is 1596 bp long with 13 exons and 12 introns (Fig. 1a) and encodes a protein of 531 amino acids. Six residues were different between lines 178 and B73 (Fig. S2). The protein has an estimated molecular mass of $55.96 \mathrm{kDa}$ and pl 9.59 and likely to contain 11 transmembrane spanning regions (Table 1). A multiple sequence alignment found that ZmMATE6 shared more than $30 \%$ identity at the amino acid level with ZmMATE1, SbMATE, HvAACT1 and OsFRDL4 (Fig. 1b). The 50 amino acid domain between A114 to I163 forms the citrate exuding motif (CEM) and the smaller region between P150 and I163 is a cytoplasmic loop (Fig. 1). Both of these domains have been linked with the subset of MATE proteins involved with citrate transport [27, 47]. 
Table 1

Predictions for the number of transmembrane regions (TMR) in ZmMATE6 and its subcellular localization.

\section{Predictions for the transmembrane regions of ZmMATE6}

\begin{tabular}{|c|c|c|}
\hline Program & TMRs & Online linkage \\
\hline TMHMM & 9 & $\begin{array}{l}\text { http://www.cbs.dtu.dk/cgi-bin/webface2.fcgi? } \\
\text { jobid=5F686608000011CF37D23A6D\&wait }=20\end{array}$ \\
\hline TCDB & 11 & http://www.tcdb.org/progs/TMS.php \\
\hline TMpred & 11 & https://embnet.vital-it.ch/cgi-bin/TMPRED_form_parser \\
\hline SOSUl & 11 & http://harrier.nagahama-i-bio.ac.jp/sosui/cgi-bin/adv_sosui.cgi \\
\hline НMMTOP & 11 & http://www.enzim.hu/hmmtop/server/hmmtop.cgi \\
\hline \multicolumn{3}{|c|}{ Predictions for the subcellular location of ZmMATE6 } \\
\hline Program & Location & Online linkage \\
\hline YLoc & Chlorop & https://abi-services.informatik.uni-tuebingen.de/yloc/webloc.cgi \\
\hline Cell-PLoc2.0 & PM & http://www.csbio.sjtu.edu.cn/cgi-bin/PlantmPLoc.cgi \\
\hline WoLFPSORT & $\begin{array}{l}\text { Chlorop, } \\
\text { PM }\end{array}$ & $\begin{array}{l}\text { https://www.genscript.com/tools/wolf-psort/detail? } \\
\text { file=2020/09/06/htdocs/results/159944442328764.detailed1.html\#159944442328764 }\end{array}$ \\
\hline BUSCA & Mitochon & http://busca.biocomp.unibo.it/33ebe09c-e5fd-48e8-8bda-140d40b3d1cc/showresult/ \\
\hline
\end{tabular}

A phylogenetic analysis was performed to compare ZMMATE6 with a range of other MATE genes including some that are known to transport citrate and linked with either aluminum resistance or iron nutrition (Table S2). Figure 2 shows that ZmMATE6 is included in the major clade that contains all members possessing the CEM domain, including ZmMATE1. Interestingly, within this larger clade, ZmMATE6 and another protein from rye, ScMATE3, separate early from the main cluster and become distinct lineages.

\section{Distribution of pattern of ZmMATE6 expression in maize}

A previous genome wide analysis showed that ZmMATE6 expression was induced in roots by Al treatment [46]. To confirm this result ZmMATE6 expression was first measured in the root tips of the Al-resistant inbred line 178 using quantitative RT-PCR. In the control treatment (-Al), ZmMATE6 expression was low but detectable and was increased by $\mathrm{AlCl}_{3}$ treatment ( $\mathrm{pH} 4$.2) (Fig. 3a). Expression was induced up to $20 \mu \mathrm{M}$ Al but then saturated at higher concentrations at levels 2.5-fold greater than controls.

We then investigated whether this response was specific for the $\mathrm{Al}^{3+}$ cation or whether different forms of $\mathrm{Al}$ or other cations can also induce ZmMATE6 expression in the same way. Al ions hydrolyse in solution and the molar fraction of several different soluble ions change as $\mathrm{pH}$ changes. Below $\mathrm{pH} 4.5$, most $\mathrm{Al}$ exists as $\mathrm{Al}^{3+}$ which is largely responsible for the toxicity to plants in acidic soils. At values above $\mathrm{pH} 4.5$, the molar fraction of $\mathrm{Al}^{3+}$ declines rapidly and the $\mathrm{AlOH}^{2+}$ and $\mathrm{Al}(\mathrm{OH})_{2}{ }^{+}$species become more prevalent [48]. We measured ZmMATE6 expression in the root tips of plants treated with $60 \mu \mathrm{M} \mathrm{AlCl}_{3}$ at $\mathrm{pH} 4.2$ and $\mathrm{pH}$ 5.6. At pH 5.6, no induction of ZmMATE6 expression was detected whereas at pH 4.2 treatment with $60 \mu \mathrm{M} \mathrm{AlCl}_{3}$ significantly induced expression by $50 \%$ and $60 \mu \mathrm{M} \mathrm{AlCl}_{3}$ induced expression by $350 \%$ (Fig. 3b). These results indicate that $\mathrm{Al}^{3+}$ could induce $\mathrm{ZmMATE6}$ expression but $\mathrm{AlOH}^{2+}$ and $\mathrm{Al}(\mathrm{OH})_{2}^{+}$could not. We then tested whether a range of other divalent and trivalent cations including cadmium (Cd), lanthanum (La), zinc (Zn), 
copper $(\mathrm{Cu})$, manganese $(\mathrm{Mn})$ or iron $(\mathrm{Fe})$ could induce expression. None of these cations were able to induce ZmMATE6 expression in the same way as $\mathrm{Al}^{3+}$.

The time-dependence of ZmMATE6 expression in Al-resistant and Al-sensitive genotype was measured through time in different plant tissues. The Al-resistant line 178 and the Al-sensitive line $\mathrm{B} 73$ were treated with $60 \mu \mathrm{M} \mathrm{AlCl}_{3}(\mathrm{pH} 4.2)$ and expression was measured through time in the root tips (RT, apical $10 \mathrm{~mm}$ ), the rest of roots (ROR) and the leaves (L). ZmMATE6 expression was detected in the roots and leaves of both genotypes and Al treatment steadily increased expression levels over approximately $12 \mathrm{~h}$ before declining again (Fig. $4 \mathrm{a}$ and $4 \mathrm{~b}$ ). While some variation in expression was detected between different tissues through time, we conclude that the expression in the Al-resistant and sensitive maize lines generally displayed similar patterns.

\section{Examining ZmMATE6 expression with promoter-GUS fusions}

To confirm these expression patterns, a $1.5 \mathrm{~kb}$ gDNA sequence upstream of the ZmMATE6 start codon was isolated and fused with the GUS reporter gene in an expression plasmid. The construct was transformed into Arabidopsis thaliana using the Agrobacterium-mediated method. Figures 5a-5c show that, in the absence of Al stress, GUS staining was low but detectable in the root tips, mature roots and leaves. After exposure to $60 \mu \mathrm{M} \mathrm{AlCl}_{3}(\mathrm{pH} 4.5)$ for $9 \mathrm{~h}$, GUS staining clearly increased in all tissues with stronger staining occurring in the mature root tissue than the root tips (Fig. $5 \mathrm{~d}-5 \mathrm{f})$. These results confirm the qRT-PCR results and suggest that the $1.5 \mathrm{~kb}$ region of sequence upstream of ZmMATE6 contains all the promoter information required to mimic the expression patterns observed in maize plants.

\section{Subcellular localization of ZmMATE6}

The ZmMATE6 protein is predicted to have multiple transmembrane regions and therefore is likely to localize to a membrane. Several predictive algorithms were utilized to determine the sub-cellular localization of the protein but the results were inconsistent. Some algorithms predicted localization of ZmMATE6 to the plasma membrane while others targeted the mitochondria or chloroplast (Table 1). In an attempt to determine the subcellular localization experimentally, we fused the GFP reporter gene to the $3^{\prime}$-terminus of the ZmMATE6 coding region and ligated it into the pCAMBIA2300 plasmid with the CaMV35S promoter to drive expression (35S:ZmMATE6::GFP). A control construct consisted of CaMV35S promoter driving expression of GFP alone (pCAMBIA2300-eGFP). Both constructs were transiently expressed in Nicotiana benthamiana leaves and protoplasts prepared from maize leaves. Fluorescence signals showed that the soluble GFP control localized to the cytoplasm and the nucleus in both cell types as expected (Fig. S3). Fluorescence from 35S:ZmMATE6:GFP constructs, however, was again inconclusive. Fluorescent signals were detected in the periphery of the tobacco cells and maize protoplasts and on some internal structures. These signals were not typical of the soluble GFP control and they could not be clearly linked with another membrane or organelle (Fig. S3). Neither transient expression system could confidently determine the sub-cellular localization of ZmMATE6 protein in these experiments.

\section{Expression of ZmMATE6 in Arabidopsis increases citrate release and Al resistance}

To investigate the function of ZmMATE6, the coding region was expressed in the Arabidopsis thaliana Columbia-0 (Col0) using the CaMV35S promoter (Fig. S4). Seven independent $T_{0}$ plants were selected and presence of the transgene was confirmed using PCR (Fig. 6a). The ZmMATE6 expression in leaf of these lines was four to 12-fold greater than the wild type control (Fig. 6b). Three $\mathrm{T}_{0}$ lines (\#1, \#4 and \#6) were selected to generate homozygous $\mathrm{T}_{3}$ lines for further experiments.

MATE genes from other species whose expression is induced by Al often function as citrate transporters (see Introduction). We therefore measured the release of organic acids from the roots of $14 \mathrm{~d}$ old transgenic Arabidopsis 
seedlings with and without $\mathrm{Al}$ treatment. In the control treatment $(0.5 \mathrm{mM} \mathrm{CaCl}, \mathrm{pH} 4.5)$ only malate and citrate were detected. Malate release was 0.02 pmol plant ${ }^{-1} 12 \mathrm{~h}^{-1}$ for all genotypes (data not shown) and citrate release was 0.3 nmol plant ${ }^{-1} 12 \mathrm{~h}^{-1}$ for all genotypes (Fig. $6 \mathrm{c}$ ). When plants were treated with $60 \mu \mathrm{M} \mathrm{AlCl}_{3}(\mathrm{pH} 4.5)$ malate release remained unchanged whereas citrate release was significantly increased in all genotypes but the increases were significantly larger in the transgenic lines than wild-type. Wild-type plants increased citrate release by four-fold to 1.3

nmol plant ${ }^{-1} 12 \mathrm{~h}^{-1}$ whereas the two transgenic lines tested increased release by ten-fold to approximately $2.8 \mathrm{nmol}$ plant $^{-1} 12 \mathrm{~h}^{-1}$ (Fig. 6c).

To determine whether the increase in citrate release affected Al resistance of the transgenic Arabidopsis, seedlings were transferred to plates containing 0 or $100 \mu \mathrm{M} \mathrm{AlCl}_{3}$ and grown for a further four days (Fig. 7a). Root growth of the wildtype and transgenic Arabidopsis lines was similar in the absence of Al. In the presence of $100 \mu \mathrm{M} \mathrm{Al,} \mathrm{net} \mathrm{root} \mathrm{growth} \mathrm{was}$ inhibited in all genotypes but the inhibition was significantly greater in the wild-type control than the transgenic lines (Fig. 7a, b). Relative root elongation (RRE) was less than $10 \%$ for wild-type plants compared to $46 \%, 58 \%$ and $86 \%$ for the three transgenic lines (Fig. 7c).

We tested whether the enhanced resistance to Al toxicity observed in the transgenic lines was associated with a reduction accumulation of $\mathrm{Al}$ in the roots and shoots. The first experiment estimated $\mathrm{Al}$ uptake by staining roots with hematoxylin. This compound turns a blue-purple colour when it chelates $\mathrm{Al}$, so a darker stain indicates more $\mathrm{Al}$ is present in the tissue. Seedlings were treated with 0 or $60 \mu \mathrm{M} \mathrm{AlCl}_{3}$ for $12 \mathrm{~h}$ and the roots stained with hematoxylin (Fig. $8 \mathrm{a}$ ). In control solution, the staining was very faint but it became darker in the root tips and mature roots after treatment with Al. The staining was less intense in the three transgenic lines than the wild-type plants, especially at the root tips (Fig. 8a). These results suggest that less $\mathrm{Al}$ accumulates in the roots of the transgenic lines than the wild-type controls. We quantified these differences by measuring the Al concentration in the roots before and after Al treatment using ICP-MS. In the control treatment, the transgenic lines and wild-type plants contained similar concentrations of Al of approximately $2.5 \mathrm{mg} \mathrm{gDW}^{-1}$ (Fig. 8b). These concentrations increased in all lines after exposure to Al but the transgenic lines accumulated less than $30 \%$ of the Al that the wild-type plants accumulated. Al content in leaves was similar in all lines and did not change with Al treatment (Fig. S5). These results suggest that overexpression of ZmMATE6 increased Al resistance by reducing Al accumulation in the roots.

\section{Discussion}

This study investigated the function of ZmMATE6 in maize. We established that ZmMATE6 is widely expressed in maize tissues including in the root tips, mature roots and leaves. Expression was induced by $\mathrm{Al}^{3+}$ but not by other cations tested. The distribution of expression and the induction by $\mathrm{Al}^{3+}$ were confirmed using transgenic Arabidopsis plants expressing GUS using the ZmMATE6 promoter. Induction peaked after $12 \mathrm{~h}$ of Al treatment which differs from Zhu et al [46] who found maximum expression after $6 \mathrm{~h}$. This difference is likely related to experimental conditions since Zhu et al [46] used a more severe treatment consisting of $222 \mu \mathrm{M} \mathrm{AIK}\left(\mathrm{SO}_{4}\right)_{2}$ at $\mathrm{pH} 4.0$. The finding that ZmMATE6 is widely expressed throughout the plant, and not just at the root tips, does not preclude it from being involved in Al resistance. Several MATEs that confer Al resistance in other species are expressed throughout the roots and even in the leaves. Examples of these include ZmMATE1 in maize [33], HvAACT1 in barley [49], TaMATE1B in wheat [37], BoMATE in Brassica oleracea [38] and OSFRDL2 in rice [50].

The subcellular location of ZmMATE6 could not be established with confidence in this study despite expressing GFPtagged proteins in two experimental systems. Even the online algorithms were inconsistent in their predictions which may suggest ZmMATE6 localizes to several different membranes. Nevertheless, Arabidopsis plants expressing ZmMATE6 under the CaMV35S promoter showed significantly greater citrate release which suggests some protein is 
localizing to the plasma membrane. Citrate release from these transgenic lines was low in control conditions (-Al) and similar to wild-type plants. Al treatment enhanced citrate release from the transgenic and control plants but the magnitude of increase from the transgenic lines was two-fold greater than from wild-type plants. By contrast, malate release was not affected by Al treatments which demonstrates that citrate exudation was a regulated transport process and not a result of general leakage from damaged tissues.

The finding that ZmMATE6 transports citrate is consistent with it possessing the citrate exuding motif (CEM) and a specific region forming a cytoplastic loop because both domains have been associated with the subset of MATE proteins that function as citrate cotransporters $[27,47]$. The fifth aspartate (D) residue in the CEM plays an important role in organic cation transport activity because the transport function was lost when this residue was substituted for an asparagine in SbMATE $[27,51]$. Interestingly, the fifth residue in the CEM domain of ZmMATE6 is a glutamate (E) which indicates that this more conservation substitution (aspartate and glutamateare both anionic residues) does not inhibit function. Phylogenetic analysis placed ZmMATE6 in the large cluster with other MATEs known to confer Al resistance (e.g. SbMATE, HvAACT1, TaMATE1B and OsFRDL4) but ZmMATE6 was soon separated from the others and placed on a branch by itself. This suggests that ZmMATE6 has a different evolutionary lineage and perhaps additional functions from the others.

The finding that Al treatment increased citrate release from the transgenic Arabidopsis lines constitutively expressing ZmMATE6 indicates that Al not only induces ZmMATE6 expression in maize but also triggers the activity of the ZmMATE6 transporter. In this respect, ZmMATE6 shows similarities with SbMATE in sorghum because Al induces the expression of SbMATE and activates the transport function of that protein [30, 52]. ZmMATE6 differs from ZmMATE1 [33] and VuMATE in rice bean [19] because, although Al induces the expression of their genes, it is not required to activate protein function. ZmMATE6 also differs from TaMATE1B in wheat which is neither induced nor activated by Al $[37,53]$. We should be mindful that determining whether Al induces MATE expression and/or activates protein function cannot be done in situ because the two processes cannot be distinguished. Instead, the genes need to be expressed in a heterologous system like Xenoupus oocytes or other model species like Arabidopsis using a constitutive promoter and then the effect of Al treatment assessed. Therefore, it is possible that the function of these transporters in other cell types do not reflect their function in situ due to differences in post-translational modifications, missing cofactors or signaling pathways [54].

Some results presented here support a role for ZmMATE6 in the Al resistance of maize. These include the findings that ZmMATE6 is induced by Al treatment and that the ZmMATE6 protein is activated by Al to transport citrate out of cells. Additionally, transgenic plants expressing ZmMATE6 accumulate less Al in their roots and are more resistance to Al stress. Other results are not consistent with ZmMATE6 performing a major role in Al resistance. ZmMATE6 is located on chromosome 3 and therefore is not associated with the five QTL identified by Ninamango-Cárdenas [44]. However, ZmMATE6 could still have linked been with Al resistance if it represented an additional resistance gene that was not segregating in the biparental population examined by Ninamango-Cárdenas [44]. The parents in that population were the Al-sensitive inbred line L53 and the Al-resistant inbred line L1327 and Al resistance phenotype linked with ZmMATE6 (if it is a resistance gene) would not be detected if neither parent possessed the resistant allele for ZmMATE6 or if both parents possessed the same allele of ZmMATE6. Another result that is initially inconsistent with ZmMATE6 contributing to resistance was the finding that ZmMATE6 expression was induced by Al in an Al-resistant inbred line 178, and an Alsensitive inbred line B73, in a generally similar pattern. However, since the predicted amino acid sequences of ZmMATE6 in 178 and B73 differ by six residues it is possible that ZmMATE6 functions differently in these two lines, such that it is less effective at releasing citrate in B73. This question will be resolved in future studies by expressing the ZmMATE6 gene from B73 and other sensitive and resistant lines in a heterologous expression system and comparing their transport functions directly. It is also important to determine whether other major resistance mechanisms are operating in these lines and obscuring more subtle contributions from ZmMATE6. This could be achieved by generating a segregating 
population between 178 and B73 and assessing whether Al resistance can be linked with ZmMATE6 on chromosome 3 . Those results will help determine whether or not ZmMATE6 contributes to the baseline level of Al resistance or maize or even accounts for some of the genotypic variation in this trait.

\section{Conclusion}

ZmMATE6 is another MATE gene which is involved in Al-induced secretion of citrate from the roots after ZmMATE1. Overexpression of ZmMATE6 enhances the resistance to Al toxicity in transgenic Arabidopsis plants by mediating root citrate efflux.

\section{Materials And Methods}

\section{Plant materials and culture conditions}

The Al-tolerant maize inbred line 178 and the Al-sensitive inbred line B73 were used in this study [55]. Seedling cultivation were carried out as described [56].

For measuring ZmMATE6 expression during different cation treatments, the seedlings of 178 with two leaves were subjected to the nutrient solution ( $\mathrm{pH}$ 4.2) with $30 \mu \mathrm{M} \mathrm{CdCl}_{2}, 2.0 \mu \mathrm{M} \mathrm{CuCl}_{2}, 10 \mu \mathrm{M} \mathrm{LaCl}_{3}, 100 \mu \mathrm{M} \mathrm{ZnCl}_{2}, 200 \mu \mathrm{M} \mathrm{MnSO}$, $20 \mu \mathrm{M} \mathrm{FeCl}_{3}$ or $60 \mu \mathrm{M} \mathrm{AlCl}_{3}$ for $6 \mathrm{~h}$. For the time-course treatment, seedlings were subjected to $60 \mu \mathrm{M} \mathrm{AlCl}{ }_{3}\left(\mathrm{pH}_{4}\right.$.2) for 0 , $3 \mathrm{~h}, 6 \mathrm{~h}, 12 \mathrm{~h}, 24 \mathrm{~h}, 36 \mathrm{~h}, 48 \mathrm{~h}$ and $72 \mathrm{~h}$. For the Al concentration dependence experiment, seedlings were treated to 0,10 $\mu \mathrm{M}, 20 \mu \mathrm{M}, 40 \mu \mathrm{M}, 60 \mu \mathrm{M}, 80 \mu \mathrm{M}$ and $100 \mu \mathrm{M} \mathrm{AlCl}_{3}(\mathrm{pH}$ 4.2) for $6 \mathrm{~h}$. The roots or/and the shoots from all the treated seedlings were immediately frozen in liquid nitrogen, and stored at $-80^{\circ} \mathrm{C}$ for RNA extraction.

For root growth assays of the transgenic Arabidopsis thaliana (Columbia ecotype, Col-0), sterilized seeds were first grown on $1 / 2 \mathrm{MS}$ medium ( $\mathrm{pH} 4.5$ ), after the roots grew to about $1 \mathrm{~cm}$, the seedlings were transplanted into $1 / 8 \mathrm{MS}$ medium plates ( $\mathrm{pH} 4.5)$ with or without $100 \mu \mathrm{M} \mathrm{AlCl}_{3}$.

\section{Gene cloning and sequencing}

Based on the reference sequence of B73 cDNA, the ZmMATE6 gene was amplified by specific primers (Table S1). The multiple sequence alignment of previously reported MATEs from other plants amino acid sequences was performed by DNAMAN software. The phylogenetic analysis was inferred using MEGA 6 by the Neighbor-Joining (NJ) method with a bootstrap of 1000 replicates [57].

\section{RNA extraction and quantitative real-time RT-PCR}

Total RNA extraction and quantitative RT-PCR were performed as described before [56]. The primers were listed in Table S1. ZmGAPDH and AtACT2 were used as the reference gene. The relative expression level was calculated with the $2^{-\triangle \triangle C T}$ method [58]. Three biological replicate samples were generated, and each sample was tested at least three technical replicates.

\section{Subcellular localization}

ZmMATE6 sequence without terminator was fused to pCAMBIA2300 to establish the 35S:ZmMATE6::GFP vector. The subcellular localization was determined via transient expression of translation fusions with GFP in tobacco leaves and maize leaf protoplasts. Details were performed as the previous study [33]. 
The p35S:ZmMATE6 vector was transformed into Arabidopsis ecotype Columbia-0 (Col-0) via floral dip method mediated by Agrobacterium tumefacien strain EHA105 [59]. The positive homozygous seeds of $\mathrm{T}_{3}$ generation were used for follow experiments.

Isolation of the ZmMATE6 promoter and GUS staining

The $1.5 \mathrm{~kb}$ promoter of ZmMATE6 was amplified from the genomic DNA of 178 and inserted into the vector of PCAMBIA1305. The constructed ZmMATE6p::GUS vector was transformed into Arabidopsis as described above [59]. Finally, positive homozygous $\mathrm{T}_{3}$ seedlings were selected for 2.7 GUS staining

GUS staining was performed according to the previous study with a little modifications [60] after exposure to $60 \mu \mathrm{M}$ $\mathrm{AlCl}_{3}$ at $\mathrm{pH} 4.5$.

\section{Hematoxylin staining to assess Al accumulation in roots}

The hematoxylin method [61] was used in this study to compare the Al accumulation in transgenic Arabidopsis plants and control plants after Al treatment for $12 \mathrm{~h}$.

\section{Quantitative determination of Al content}

Two-week-old WT plants and transgenic lines grown in 2\% MGRL solution (pH 4.5) were pre-treatment with $0.5 \mathrm{mM}$ $\mathrm{CaCl}_{2}$ for 30 min and then treated with or without $60 \mu \mathrm{M} \mathrm{AlCl}_{3}$ for $12 \mathrm{~h}$. Root and shoot samples were collected, separately. Al concentrations were measured by ICP-MS (PerkinElmer, NexION 2000).

\section{Detection of organic acid exudation from roots}

Root exudates were collected after exposing the plants to the $0.5 \mathrm{mM} \mathrm{CaCl}_{2}(\mathrm{pH} 4.5)$ and $0.5 \mathrm{mM} \mathrm{CaCl}_{2}$ with $60 \mu \mathrm{M} \mathrm{AlCl}_{3}$ $(\mathrm{pH} 4.5)$ for $12 \mathrm{~h}$. Organic acid exudates were measured by Thermo Fisher U3000 HPLC (Syncronis C18, Dim 250 mm $\times$ $4.6 \mathrm{~mm}, 5 \mu \mathrm{m}$ ) utilizing a mobile phase of $0.05 \mathrm{M}$ potassium dihydrogen orthophosphate, buffered to $\mathrm{pH} 2.68$ with orthophosphoric aicd, and a UV detector at $210 \mathrm{~nm}$.

\section{Statistical analysis and reproducibility}

All experiments included at least three samples to confirm reproducibility. And all treatments were repeated 2 or 3 times. Statistical analysis including student's $t$ test was performed using the SPSS software.

\section{Abbreviations}

Al

Aluminum

MATE

Multidrug and toxic compound extrusion

PCR

Polymerase chain reaction

B73 and 178

Two maize inbred lines

CEM

The citrate exuding motif

\#1/\#4/\#6

Overexpression transgenic lines of ZmMATE6

RRE 
Relative root elongation

WT

Wide type of Arabidopsis (Col-0)

\section{Declarations}

\section{Funding}

This work was supported by the National Natural Science Foundation of China (No. 30800687 and 31071434), and the Major Project of Education Department in Sichuan (No. 15ZA0022).

\section{Author information}

\section{Affiliations}

Key Laboratory of Biology and Genetic Improvement of Maize in Southwest China of Agricultural Department, Ministry of Agriculture, Maize Research Institute, Sichuan Agricultural University, Wenjiang 611130, China

Han-mei Du, Chan Liu, Hong-jie Li, Wan-peng Hu, Wei-na Yan, Ying Huang, Bo-wen Luo, Xiao Zhang, Shi-bin Gao, Shufeng Zhou \& Su-zhi Zhang

CSIRO Agriculture and Food, GPO Box 1700, Canberra, ACT 2601, Australia

Peter R. Ryan

Crop Research Institute, Sichuan Academy of Agricultural Sciences, Chengdu 610066, China

Wen-zhu He

\section{Contributions}

Han-mei Du carried out the experiments, analyzed the data, and drafted the manuscript; Chan Liu, Hong-jie Li, Wan-peng Hu, Wei-na Yan, Ying Huang, Wen-zhu He, Bo-wen Luo, Xiao Zhang, Shu-feng Zhou and Shi-bin Gao contributed with consultation; Su-zhi Zhang designed the experiment; Su-zhi Zhang and Peter R Ryan revised the manuscript.

\section{Corresponding author}

Correspondence to Su-zhi Zhang

\section{Ethics approval and consent to participate}

Not applicable.

\section{Consent for publication}

Not applicable.

\section{Competing interests}

The authors declare that they have no competing interests.

\section{Publisher's Note}


Springer Nature remains neutral with regard to jurisdictional claims in published maps and institutional affiliations.

\section{Availability Of Data And Materials}

All data generated or analysed during this study are included in this published article and its supplementary information files. The datasets used and/or analysed during the current study are available from the corresponding author on reasonable request.

\section{References}

1. von Uexküll HR, Mutert E. Global extent, development and economic-impact of acid soils. Plant Soil. 1995;171(1):115.

2. Delhaize E, Ryan PR, Hebb DM, Yamamoto Y, Sasaki T, Matsumoto H. Engineering high-level aluminum tolerance in barley with the ALMT1 gene. Proc Natl Acad Sci USA. 2004;101(42):15249-15254.

3. Ryan PR, Tyerman SD, Sasaki T, Furuichi T, Yamamoto Y, Zhang WH et al. The identification of aluminium-resistance genes provides opportunities for enhancing crop production on acid soils. J Exp Bot. 2011;62(1):9-20.

4. Kochian LV, Pineros MA, Liu J, Magalhaes JV. Plant adaptation to acid soils: The molecular basis for crop aluminum resistance. Annu Rev Plant Biol. 2015;66:571-598.

5. Kollmeier M, Felle HH, Horst WJ. Genotypical differences in aluminum resistance of maize are expressed in the distal part of the transition zone. Is reduced basipetal auxin flow involved in inhibition of root elongation by aluminum. Plant Physiol. 2000;122:945-956.

6. Amenos M, Corrales I, Poschenrieder C, Illes P, Baluska F, Barcelo J. Different effects of aluminum on the actin cytoskeleton and brefeldin A-sensitive vesicle recycling in root apex cells of two maize varieties differing in root elongation rate and aluminum tolerance. Plant Cell Physiol. 2009;50(3):528-540.

7. Ma JF, Ryan PR, Delhaize E. Aluminium tolerance in plants and the complexing role of organic acids. Trends Plant Sci. 2001;6(6):273-278.

8. Ryan PR, Delhaize E. Adaptations to aluminium toxicity. In: Plant Stress Physiology. Edited by Shabala S. Croydon, UK: CABI; 2012: 171-195.

9. Delhaize E, Gruber BD, Ryan PR. The roles of organic anion permeases in aluminium resistance and mineral nutrition. FEBS Lett. 2007;581(12):2255-2262.

10. Kochian LV, Hoekenga OA, Pineros MA. How do crop plants tolerate acid soils? Mechanisms of aluminum tolerance and phosphorous efficiency. Annu Rev Plant Biol. 2004;55:459-493.

11. Liang C, Piñeros MA, Tian J, Yao Z, Sun L, Liu J et al. Low pH, aluminum, and phosphorus coordinately regulate malate exudation through GmALMT1 to improve soybean adaptation to acid soils. Plant Physiol.

2013;161(3):1347-1361.

12. Ryan PR, Delhaize E, Jones DL. Function and mechanism of organic anion exudation from plant roots. Annu Rev Plant Physiol Plant Mol Biol. 2001;52:527-560.

13. Ryan PR, Delhaize E, Randall PJ. Characterisation of Al-stimulated efflux of malate from the apices of Al-tolerant wheat roots. Planta. 1995;196:103-110.

14. Delhaize E, Ryan PR, P.J. R. Aluminum tolerance in wheat (Triticum aestivum L.) II. Aluminum stimulated excretion of malic acid from root apices. Plant Physiol. 1993 103:695-702.

15. Zheng SJ, Ma JF, Matsumoto H. High aluminum resistance in buckwheat - I. Al-induced specific secretion of oxalic acid from root tips. Plant Physiol. 1998;117(3):745-751. 
16. Ligaba $A$, Katsuhara $M$, Ryan PR, Shibasaka $M$, Matsumoto $H$. The BnALMT1 and BnALMT2 genes from rape encode aluminum-activated malate transporters that enhance the aluminum resistance of plant cells. Plant Physiol. 2006;142(3):1294-1303.

17. Li XF, Ma JF, Matsumoto H. Pattern of aluminium-induced secretion of organic acids differs between rye and wheat. Plant Physiol. 2000;123:1537-1543.

18. Hoekenga OA, Maron LG, Piñeros MA, Cancado GM, Shaff J, Kobayashi Y et al. AtALMT1, which encodes a malate transporter, is identified as one of several genes critical for aluminum tolerance in Arabidopsis. Proc Natl Acad Sci USA. 2006;103(25):9738-9743.

19. Yang XY, Yang JL, Zhou Y, Piñeros MA, Kochian LV, Li GX et al. A de novo synthesis citrate transporter, Vigna umbellata multidrug and toxic compound extrusion, implicates in Al-activated citrate efflux in rice bean (Vigna umbellata) root apex. Plant Cell Environ. 2011;34(12):2138-2148.

20. Eticha D, Zahn M, Bremer M, Yang Z, Rangel AF, Rao IM et al. Transcriptomic analysis reveals differential gene expression in response to aluminium in common bean (Phaseolus vulgaris) genotypes. Ann Bot. 2010;105(7):11191128.

21. Ryan PR, Dong D, Teuber F, Wendler N, Muhling KH, Liu J et al. Assessing how the aluminum-resistance traits in wheat and rye transfer to hexaploid and octoploid Triticale. Front Plant Sci. 2018;9:1334.

22. Sasaki T, Yamamoto Y, Ezaki B, Katsuhara M, Ahn SJ, Ryan PR et al. A wheat gene encoding an aluminum-activated malate transporter. Plant J. 2004;37(5):645-653.

23. Collins NC, Shirley NJ, Saeed M, Pallotta M, Gustafson JP. An ALMT1 gene cluster controlling aluminum tolerance at the Alt4 locus of rye (Secale cereale L). Genetics. 2008;179(1):669-682.

24. Sharma T, Dreyer I, Kochian LV, Piñeros MA. The ALMT family of organic acid transporters in plants and their involvement in detoxification and nutrient security. Front Plant Sci. 2016;7:1488.

25. Omote $\mathrm{H}$, Hiasa M, Matsumoto T, Otsuka M, Moriyama Y. The MATE proteins as fundamental transporters of metabolic and xenobiotic organic cations. Trends Pharmacol Sci. 2006;27(11):587-593.

26. Takanashi K, Shitan N, Yazaki K. The multidrug and toxic compound extrusion (MATE) family in plants. Plant Biotechnology. 2014;31(5):417-430.

27. Upadhyay N, Kar D, Deepak Mahajan B, Nanda S, Rahiman R, Panchakshari N et al. The multitasking abilities of MATE transporters in plants. J Exp Bot. 2019;70(18):4643-4656.

28. Morita M, Shitan N, Sawada K, Van Montagu MCE, Inze D, Rischer H et al. Vacuolar transport of nicotine is mediated by a multidrug and toxic compound extrusion (MATE) transporter in Nicotiana tabacum. Proc Natl Acad Sci USA. 2009;106(7):2447-2452.

29. Burko Y, Geva Y, Refael-Cohen A, Shleizer-Burko S, Shani E, Berger Y et al. From organelle to organ: ZRIZI MATE-Type transporter is an organelle transporter that enhances organ initiation. Plant Cell Physiol. 2011;52(3):518-527.

30. Magalhaes JV, Liu J, Guimaraes CT, Lana UG, Alves VM, Wang YH et al. A gene in the multidrug and toxic compound extrusion (MATE) family confers aluminum tolerance in sorghum. Nat Genet. 2007;39(9):1156-1161.

31. Wang J, Raman H, Zhou M, Ryan PR, Delhaize E, Hebb DM et al. High-resolution mapping of the Alp locus and identification of a candidate gene HVMATE controlling aluminium tolerance in barley (Hordeum vulgare L.). Theor Appl Genet. 2007;115(2):265-276.

32. Furukawa J, Yamaji N, Wang H, Mitani N, Murata Y, Sato K et al. An aluminum-activated citrate transporter in barley. Plant Cell Physiol. 2007;48(8):1081-1091.

33. Maron LG, Piñeros MA, Guimaraes CT, Magalhaes JV, Pleiman JK, Mao C et al. Two functionally distinct members of the MATE (multi-drug and toxic compound extrusion) family of transporters potentially underlie two major aluminum tolerance QTLs in maize. Plant J. 2010;61(5):728-740.

Page $13 / 22$ 
34. Silva-Navas J, Benito C, Téllez-Robledo B, Abd El-Moneim D, Gallego FJ. The ScAACT1 gene at the Q alt5 locus as a candidate for increased aluminum tolerance in rye (Secale cereale L.). Mol Breeding. 2011;30(2):845-856.

35. Yokosho K, Yamaji N, Ma JF. An Al-inducible MATE gene is involved in external detoxification of Al in rice. Plant J. 2011;68(6):1061-1069.

36. Sawaki Y, Kihara-Doi T, Kobayashi Y, Nishikubo N, Kawazu T, Koyama H et al. Characterization of Al-responsive citrate excretion and citrate-transporting MATEs in Eucalyptus camaldulensis. Planta. 2013;237(4):979-989.

37. Tovkach A, Ryan PR, Richardson AE, Lewis DC, Rathjen TM, Ramesh S et al. Transposon-mediated alteration of TaMATE1B expression in wheat confers constitutive citrate efflux from root apices. Plant Physiol. 2013;161(2):880892.

38. Wu X, Li R, Shi J, Wang J, Sun Q, Zhang H et al. Brassica oleracea MATE encodes a citrate transporter and enhances aluminum tolerance in Arabidopsis thaliana. Plant Cell Physiol. 2014;55(8):1426-1436.

39. Ma Q, Yi R, Li L, Liang Z, Zeng T, Zhang Y et al. GsMATE encoding a multidrug and toxic compound extrusion transporter enhances aluminum tolerance in Arabidopsis thaliana. BMC Plant Biol. 2018;18(1):212.

40. Santos $\mathrm{E}$, Matos $\mathrm{M}$, Benito $\mathrm{C}$. Isolation and characterization of a new MATE gene located in the same chromosome arm of the aluminium tolerance (Alt1) rye locus. Plant Biol. 2020;22(4).

41. Magalhaes JV, Gardner C, Clark R. Evaluation of inbred maize lines for aluminum tolerance in nutrient solution. In: In Genetic Aspects of Plant Mineral Nutrition. Edited by Gabelman HLB, ed. Dordrecht, The Netherlands: Martinus Nijhoff; 1987: 255-265.

42. Pandey S, Ceballos H, Magnavaca R, Bahia AFC, Duquevargas J, Vinasco LE. Genetics of tolerance to soil acidity in tropical maize. Crop Sci. 1994;34:1511-1514.

43. Borrero JC, Pandey S, Ceballos H, Magnavaca R, Bahia AFC. Genetic variances for tolerance to soil acidity in a tropical maize population. Maydica. 1995;40:283-288.

44. Ninamango-Cárdenas FE, Guimarães CT, Martins PR, Parentoni SN, Carneiro NP, Lopes MA et al. Mapping QTLs for aluminum tolerance in maize. Euphytica. 2003;130(2):223-232.

45. Maron LG, Guimaraes CT, Kirst M, Albert PS, Birchler JA, Bradbury PJ et al. Aluminum tolerance in maize is associated with higher MATE1 gene copy number. Proc Natl Acad Sci USA. 2013;110(13):5241-5246.

46. Zhu H, Wu J, Jiang Y, Jin J, Zhou W, Wang Y et al. Genomewide analysis of MATE-type gene family in maize reveals microsynteny and their expression patterns under aluminum treatment. J Genet. 2016;95(3):691-704.

47. Liu J, Magalhaes JV, Shaff J, Kochian LV. Aluminum-activated citrate and malate transporters from the MATE and ALMT families function independently to confer Arabidopsis aluminum tolerance. Plant J. 2009;57(3):389-399.

48. Kinraide TB. Identity of the rhizotoxic aluminium species. Plant soil. 1991;134:167-178.

49. Fujii M, Yokosho K, Yamaji N, Saisho D, Yamane M, Takahashi H et al. Acquisition of aluminium tolerance by modification of a single gene in barley. Nat Commun. 2012;3:713.

50. Yokosho K, Yamaji N, Fujii-Kashino M, Ma JF. Functional analysis of a MATE gene OsFRDL2 revealed its involvement in Al-induced secretion of citrate, but a lower contribution to Al tolerance in rice. Plant Cell Physiol. 2016;57(5):976-985.

51. Doshi R, McGrath AP, Pineros M, Szewczyk P, Garza DM, Kochian LV et al. Functional characterization and discovery of modulators of SbMATE, the agronomically important aluminium tolerance transporter from Sorghum bicolor. Sci Rep. 2017;7(1):17996.

52. Zhou G, Pereira JF, Delhaize E, Zhou M, Magalhaes JV, Ryan PR. Enhancing the aluminium tolerance of barley by expressing the citrate transporter genes SbMATE and FRD3. J Exp Bot. 2014;65(9):2381-2390.

53. Ryan PR, Raman H, Gupta S, Horst WJ, Delhaize E. A second mechanism for aluminu resistance in wheat relies on the constitutive efflux of citrate from roots. Plant Physiol. 2009;149:340-351.

Page $14 / 22$ 
54. Ligaba-Osena A, Fei Z, Liu J, Xu Y, Shaff J, Lee SC et al. Loss-of-function mutation of the calcium sensor CBL1 increases aluminum sensitivity in Arabidopsis. New Phytol. 2017;214(2):830-841.

55. Xu LM, Liu W, Cui BM, Wang N, Ding JZ, Liu C et al. Aluminium tolerance assessment of 141 maize germplasms in a solution culture. Universal Journal of Agricultural Research. 2017;5(1):1-9.

56. Du H, Huang Y, Qu M, Li Y, Hu X, Yang W et al. A maize ZmAT6 gene confers aluminum tolerance via reactive oxygen species scavenging. Front Plant Sci. 2020;11.

57. Tamura K, Stecher G, Peterson D, Filipski A, Kumar S. MEGA6: Molecular evolutionary genetics analysis version 6.0. Mol Biol Evol. 2013;30(12):2725-2729.

58. Livak KJ, Schmittgen TD. Analysis of relative gene expression data using real-time quantitative PCR and the $2-\Delta \Delta C T$ method. Methods. 2001;25:402-408.

59. Clough SJ, Bent AF. Floral dip: a simplifed method for Agrobacterium -mediated transformation of Arabidopsis thaliana. Plant J Cell Mol Biol. 1998;16:735.

60. Jefferson RA, Kavanagh TA, Benan MW. GUS fusions: beta-glucuronidase as a sensitive and versatile gene fusion marker in higher plants. EMBO J. 1987;6:3901-3907.

61. Ribeiro AP, de Souza WR, Martins PK, Vinecky F, Duarte KE, Basso MF et al. Overexpression of BdMATE gene improves aluminum tolerance in Setaria viridis. Front Plant Sci. 2017;8:865.

\section{Figures}


Exon - Intron

B

ZMMATE 4

SDMATE

HVAACT1

OSFRDL 4

MLRLHHH SAPVSPHAA I CP PSRLACSCICNK PNSRITASQGWS IRRRI TTVASGQSV PGYT PDDG $\ldots \ldots \ldots \ldots \ldots \ldots$ DQCLETGNKLSEA $\ldots \ldots$ MH PPT HMRARA PI GNS G PD SLSYFI PLH PLLGVWTMHGERERERES LLLL PDRSAGAMEG $\ldots \ldots \ldots \ldots \ldots \ldots \ldots$ GGE HHHPISVELR .MEEHRS PAHAKPEAE $Q P P Q Q Q V$ PAAMAVAVAVDVAAPAAL $Q N S T A A$ PAENG DVAAAGAAENGTAASAANGDGG $\ldots \ldots$ GSE LLGGPRWTGLHLEVM $\ldots \ldots \ldots \ldots \ldots \ldots$ ME EGAAASMMT GDKKWVAVV DV PADADAA TAANG G GPEEKAAE DLPAA $\ldots \ldots \ldots \ldots$ LSGCPRTTGLYLFVM MQI DELS NT CMARSS SAPE SMEADH QLT ATVTAAAS G DMPVTE QQQQKQMVAVAAPPATENADAAGGGG G DNG DHL PPT AT SLGGGARRTGLHLFVL Consensus

ZMMATE 4 ZMMATE 1

SBMATE

HVAACT 1

OSFRDL 4

Consensus

TVK̈EAFISISLNSVTC DARLAFR . WDEIL NIRSVEK. LDEIG. . AEVLGIAVDGALAMAD NIRSVEK. LDEIG. .S EVLRIAVEASIALAAD NARSALR. LDEIG. .

ZMMATE 4

ZMMATE1

SBMATE

HVAACT 1

OSFRDL 4

Consensus

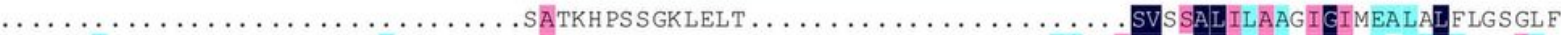

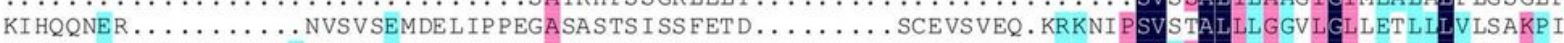

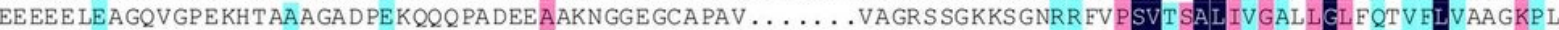

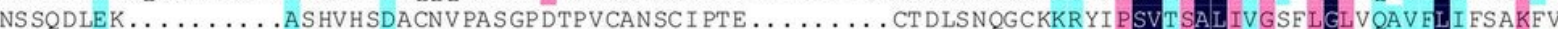
DDGH DAKG ...... HGASAAAVAD PEKQQVVGVDSAET GAEVST AAVRT T DDKKAAAAGVGVGKCRRR FV PSVT SALIVGAFL GLLQAV HLVAGKPL CEM
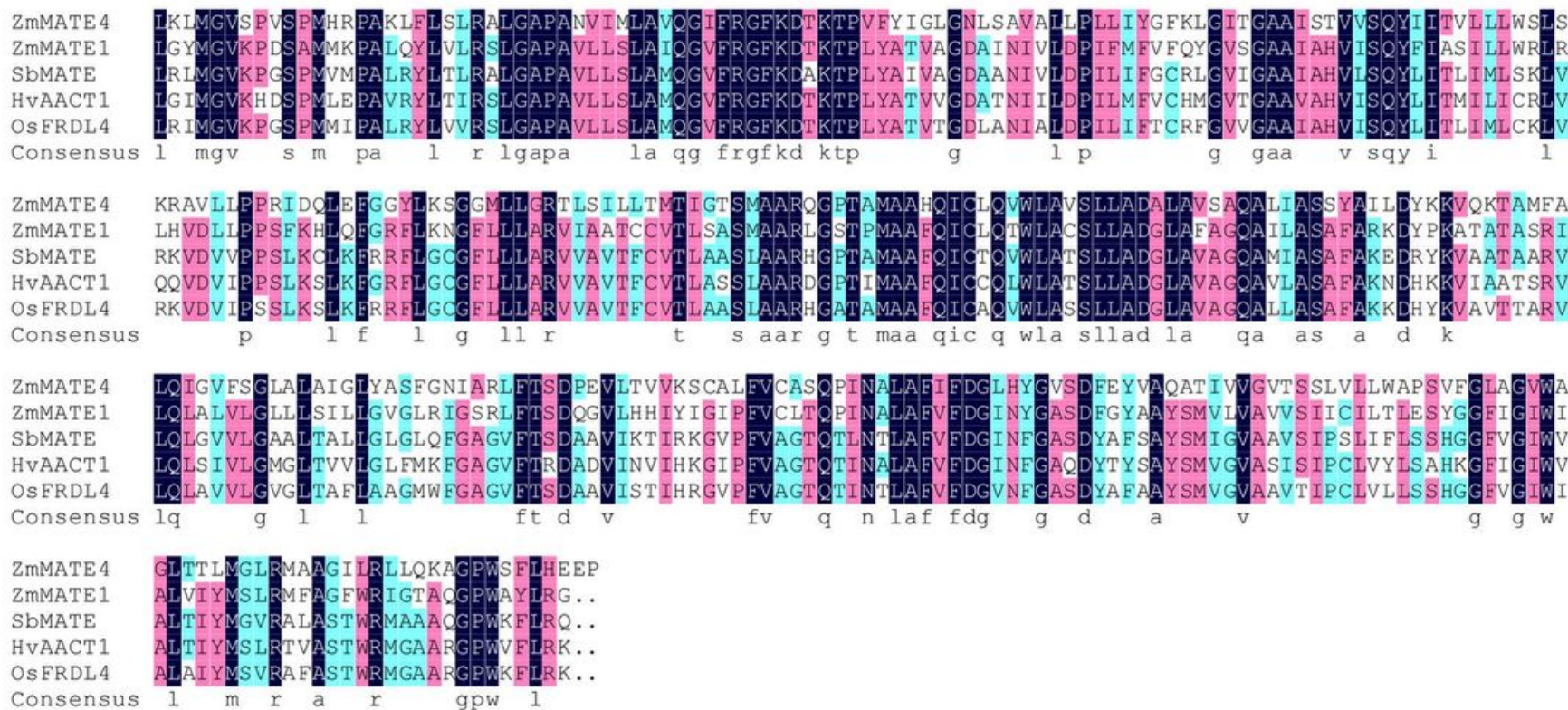

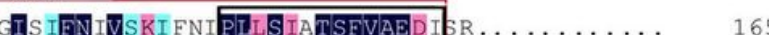
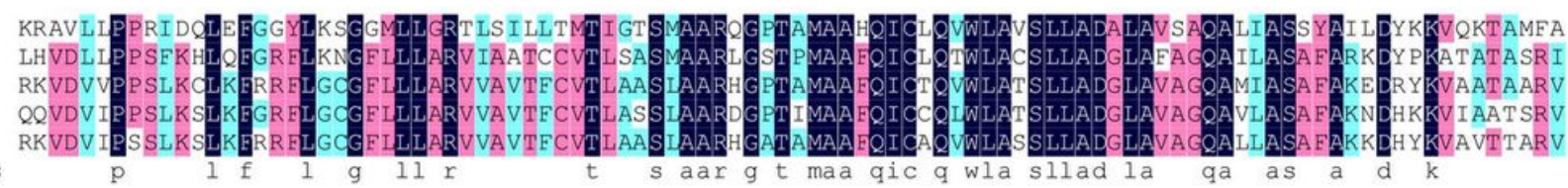

\section{Figure 1}

Sequence alignment of ZmMATE6 with other citrate transporters The citrate transporters were ZmMATE1 (ACM47309) from maize, SbMATE (XP_021311565) from sorghum, HvAACT1 (ANN88344) from barley and OsFRDL4 (BAS75911) from rice. Identical (100\%), conservative $(75 \%-99 \%)$ and blocks $(50 \%-74 \%)$ of similar amino acid residues are shaded in deep blue, cherry red, and cyan, respectively. The conserved CEM and REF motifs are indicated by red and black boxes, respectively. 


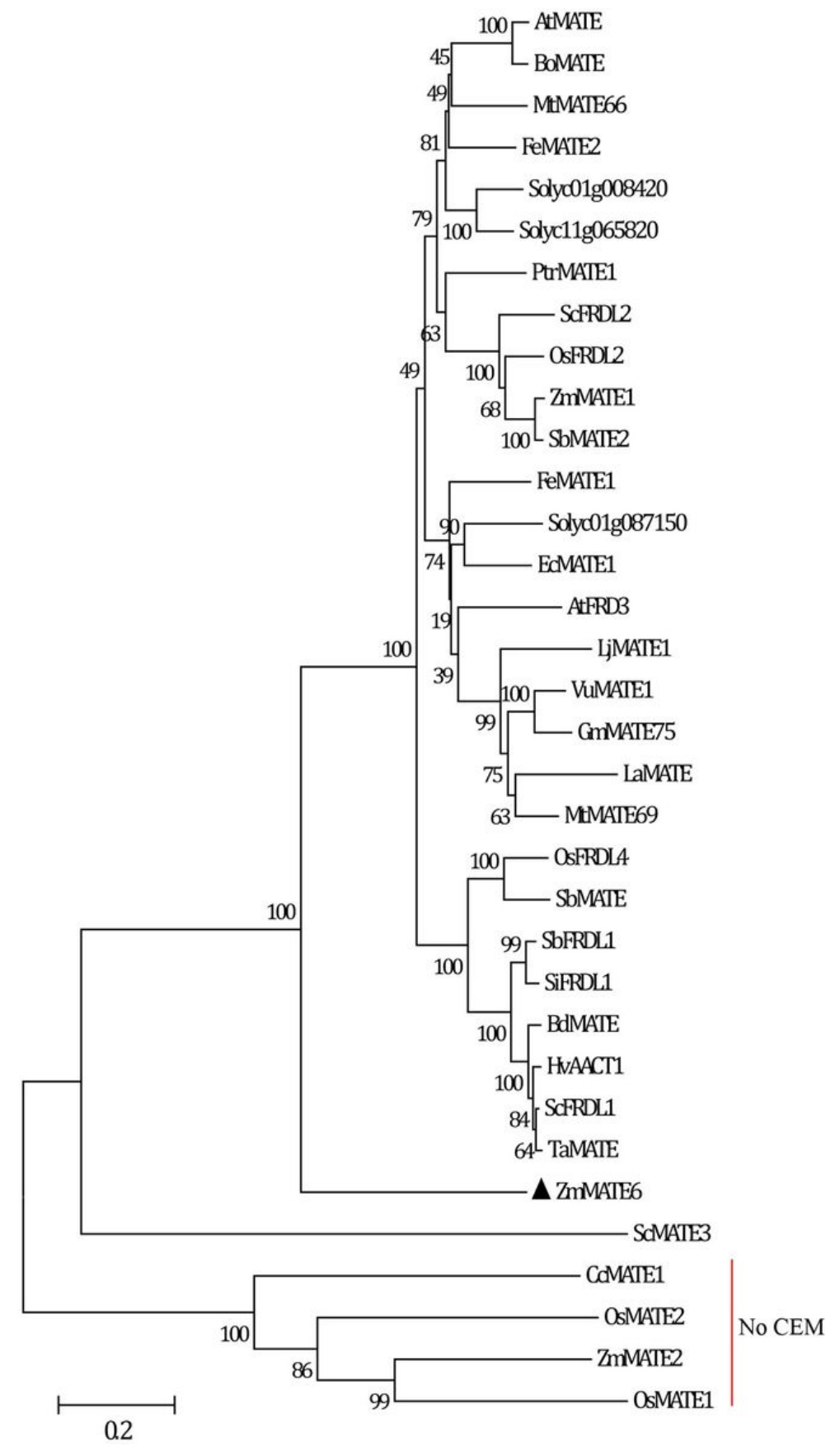

Figure 2

Phylogenetic analysis of ZmMATE6 

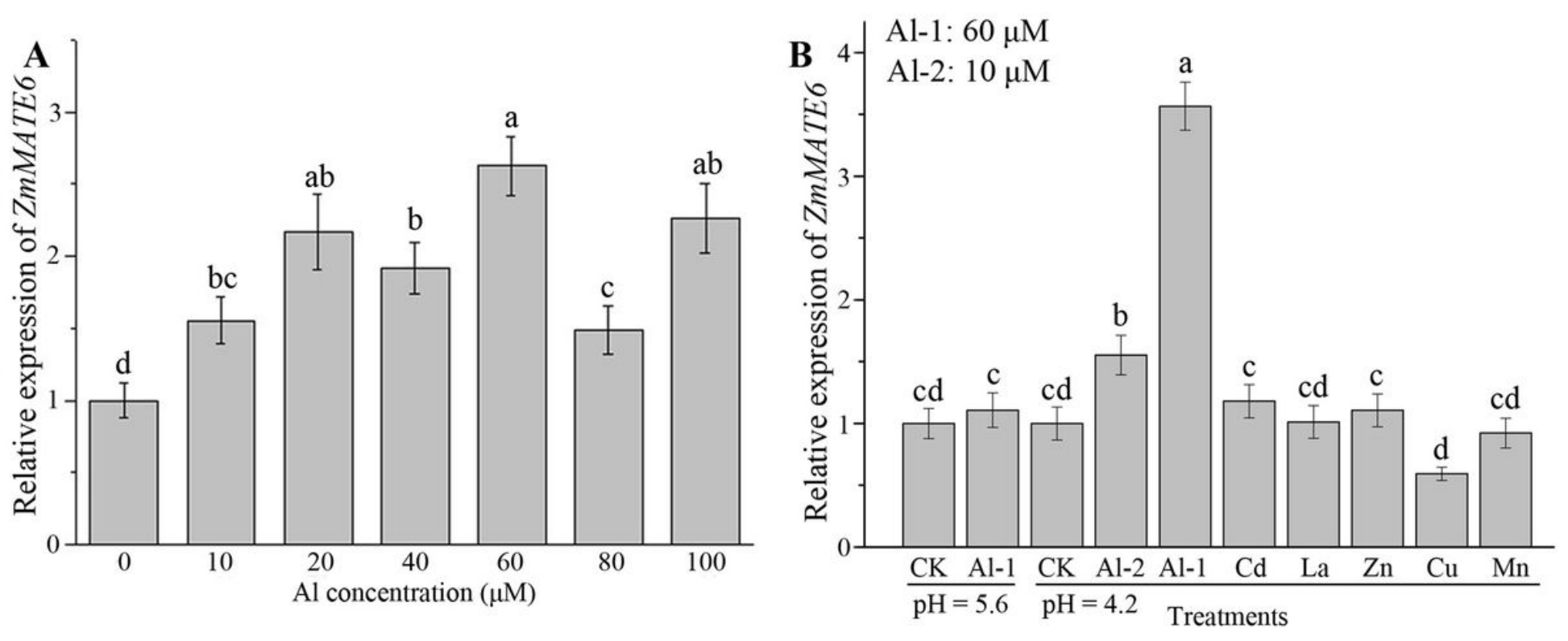

Figure 3

Expression pattern of ZmMATE6 gene in maize roots (A) Concentration effect of Al treatment on ZmMATE6 expression. Seedlings of the maize inbred line 178 were treated for 6 h by $0,10 \mu \mathrm{M}, 20 \mu \mathrm{M}, 40 \mu \mathrm{M}, 60 \mu \mathrm{M}, 80 \mu \mathrm{M}$ and $100 \mu \mathrm{M}$ Al. (B) Effect of other cations on ZmMATE6 expression. Seedlings were exposed for $6 \mathrm{~h}$ to a $0.5 \mathrm{mM} \mathrm{CaCl} 2$ solution (pH 4.2) containing $30 \mu \mathrm{M} \mathrm{CdCl} 2,2.0 \mu \mathrm{M} \mathrm{CuCl} 2,10 \mu \mathrm{M} \mathrm{LaCl} 3,100 \mu \mathrm{M} \mathrm{ZnCl} 2,200 \mu \mathrm{M} \mathrm{MnSO} 4,20 \mu \mathrm{M} \mathrm{FeCl} 3$ and $60 \mu \mathrm{M}$ AlCl3, respectively. ZmGAPDH was used as internal control. The values were presented as mean $\pm S D(n=3)$ and marked with different letters to indicate statistic significant difference at $\mathrm{P}<0.05$ (student's t test).
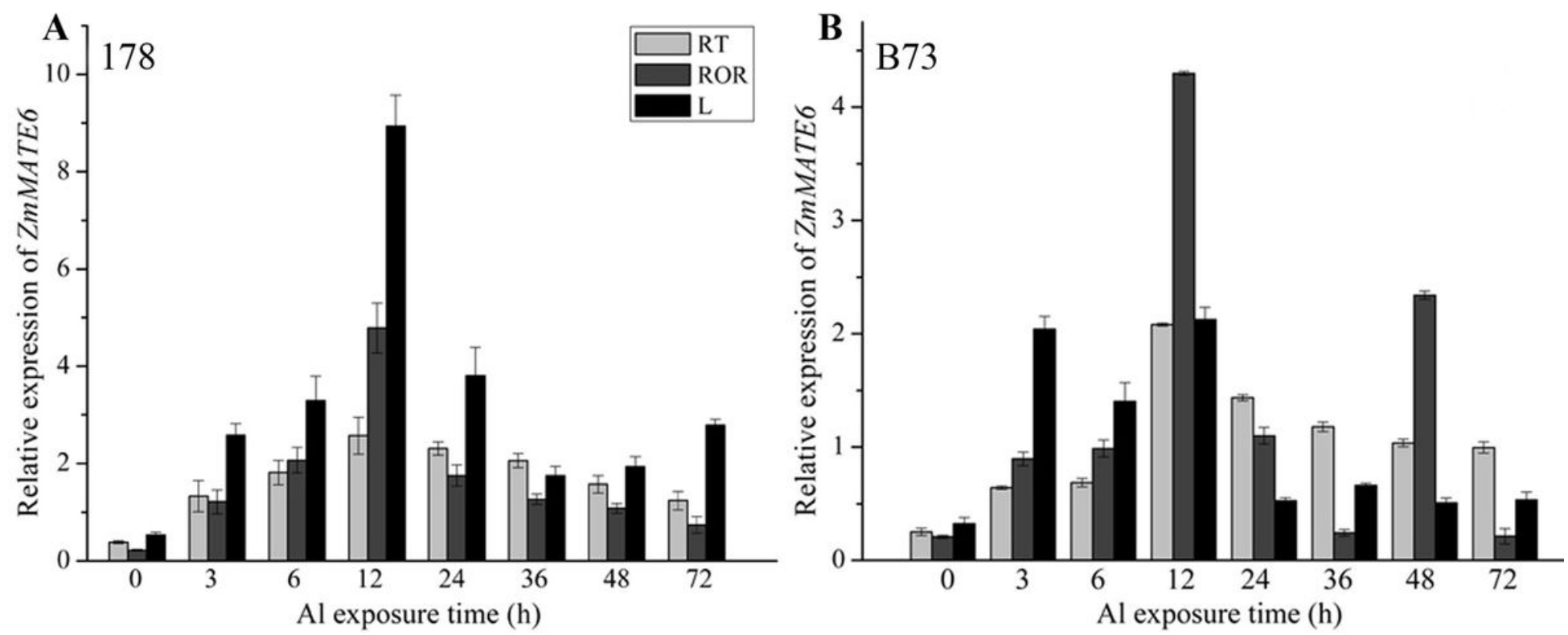

Figure 4

Tissue specificity of expression of ZmMATE6 in different genotype Transcription of ZmMATE6 in maize inbred line (A) 178 (Al-tolerance) and (B) B73 (Al-sensitive) seedlings, including root tips (R), the rest of root (ROR) and leaves (L) were quantified at $0,3 \mathrm{~h}, 6 \mathrm{~h}, 12 \mathrm{~h}, 24 \mathrm{~h}, 36 \mathrm{~h}, 48 \mathrm{~h}$ and $72 \mathrm{~h}$ after exposure to $60 \mu \mathrm{M} \mathrm{AlCl} 3$ (pH 4.2). ZmGAPDH was used as internal control. The values were presented as mean \pm SD $(n=3)$. 

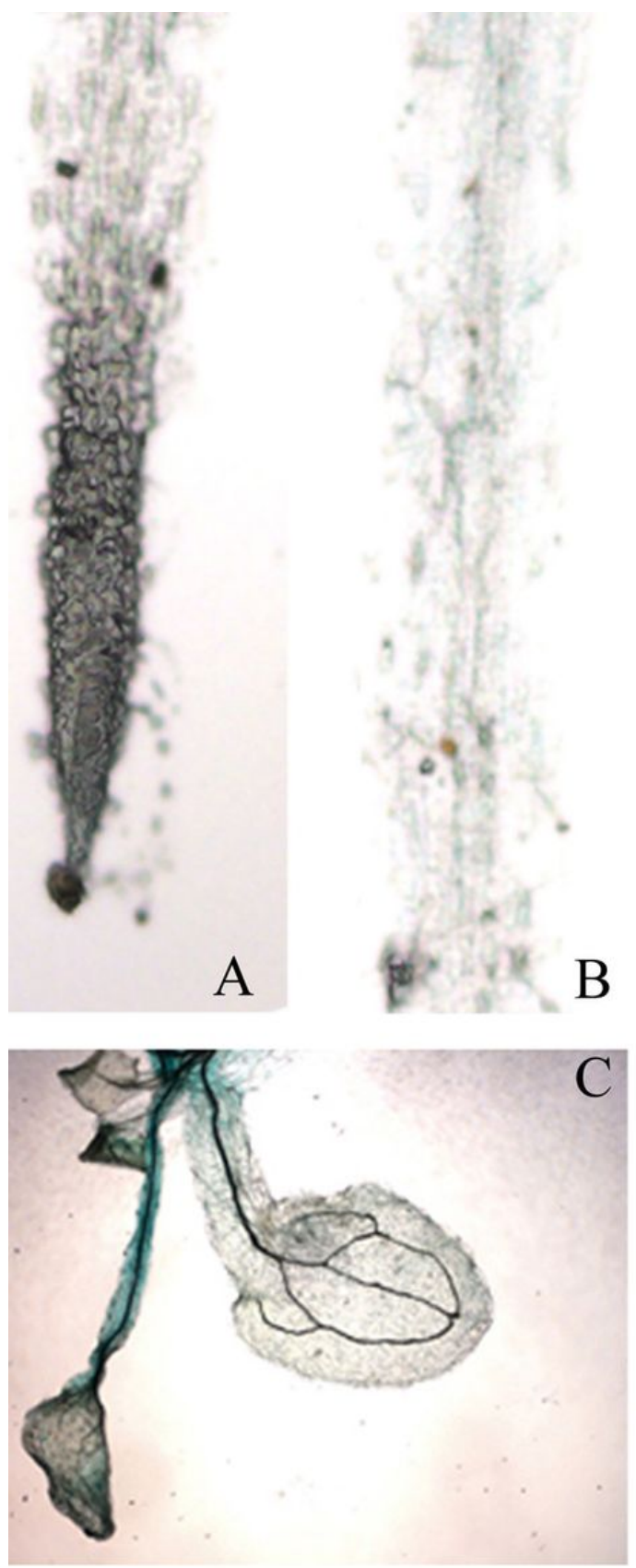

$0 \mathrm{Al}$

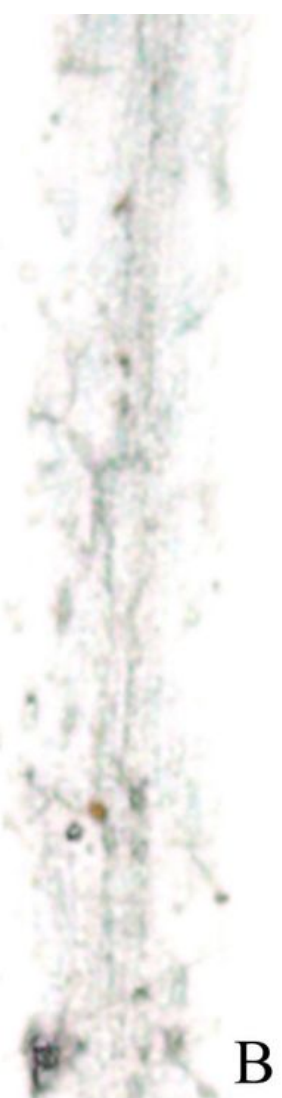

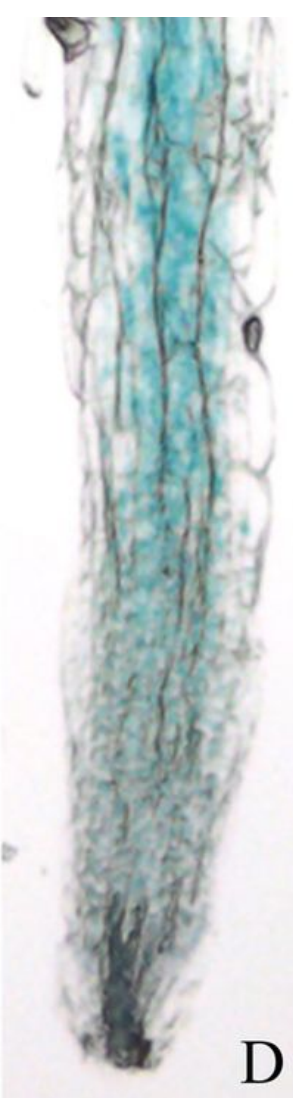
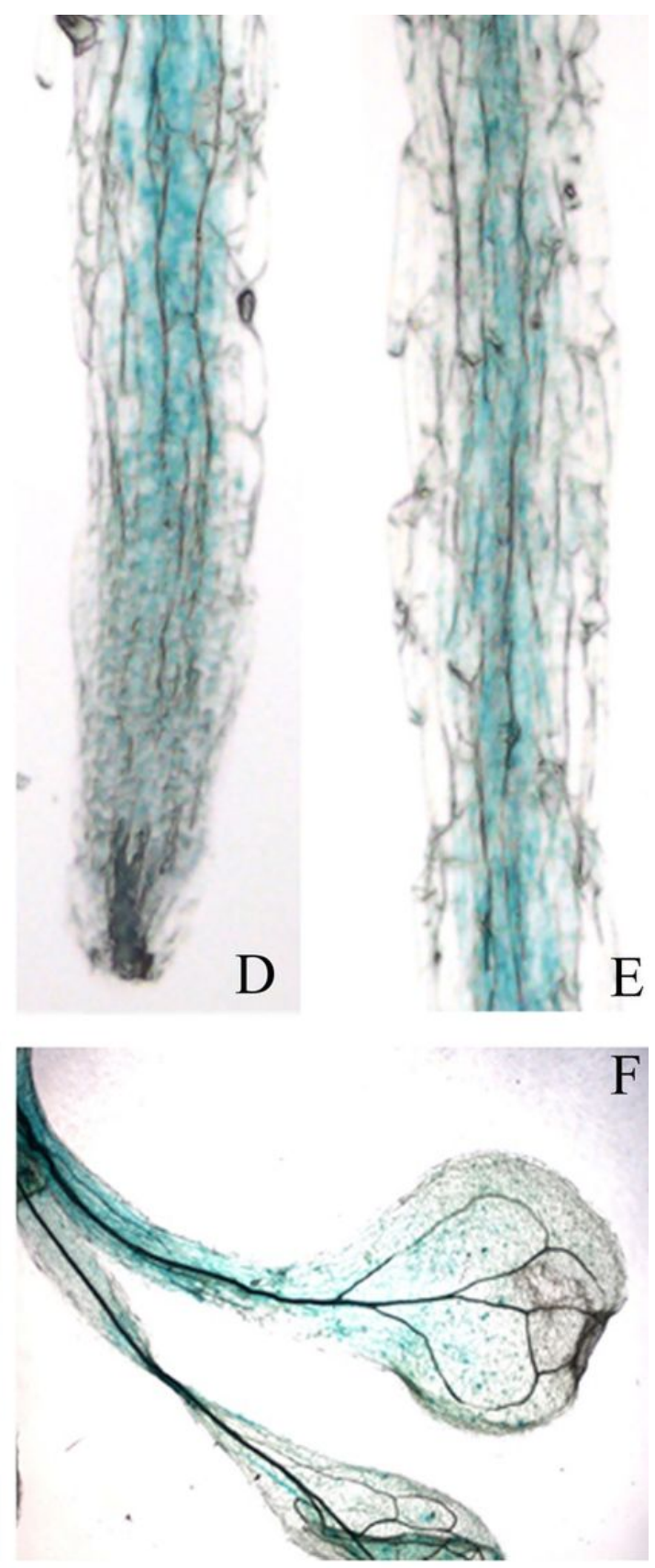

$60 \mu \mathrm{M} \mathrm{Al}$

\section{Figure 5}

ZmMATE6p::GUS expression in transgenic plants The transgenic Arabidopsis was cultured with 2\% MGRL (pH 5.6) nutrient solution for $7 \mathrm{~d}$, and then treated with or without $60 \mu \mathrm{M} \mathrm{AlCl} 3$ for $0 \mathrm{~h}(\mathrm{~A}, \mathrm{~B}, \mathrm{C})$ and $9 \mathrm{~h}(\mathrm{D}, \mathrm{E}, \mathrm{F})$. A and $D$ showed the root apex, $\mathrm{B}$ and $\mathrm{E}$ show the mature zone. $\mathrm{C}$ and $\mathrm{F}$ showed the leaves. 

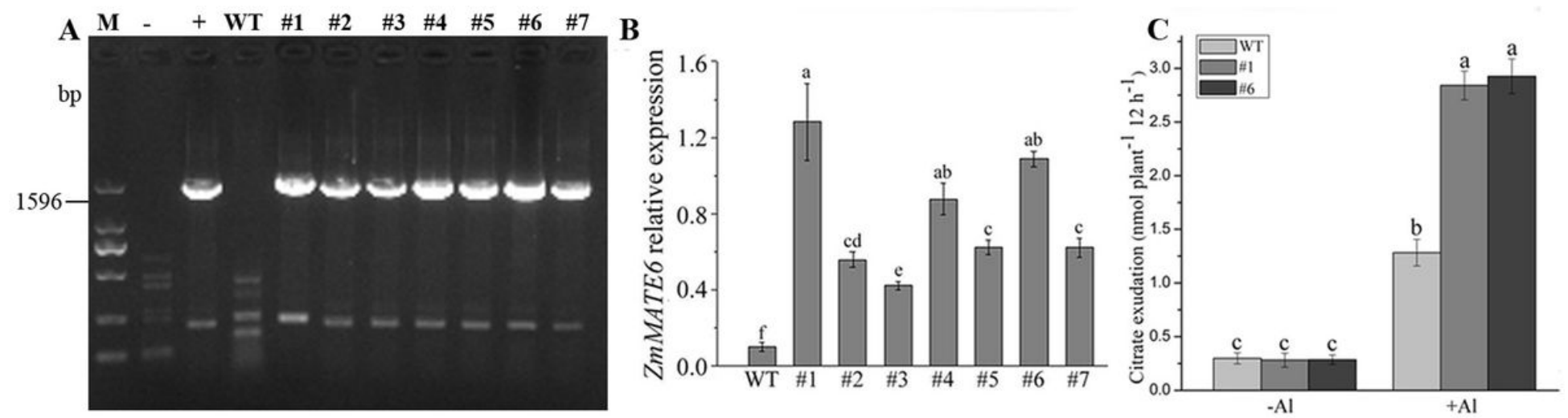

\section{Figure 6}

Transgenic Arabidopsis expressing ZmMATE6 release citrate Arabidopsis was transformed with ZmMATE6 using the CaMV35S promoter. (A) PCR analyses of seven transgenic Arabidopsis events (T0), [M-2000 bp DNA ladder; -: negative control (water), +: positive control (binary plasmid), WT: wild type Arabidopsis]; (B) Relative expression of ZmMATE6 in the T0 plants using RT-PCR where AtACT2 was the internal reference control; (C) Organic anion release from roots of transgenic Arabidopsis with and without $60 \mu \mathrm{M} \mathrm{AICl3}(\mathrm{pH} 4.5)$. Values represent mean $\pm \mathrm{SD}(\mathrm{n} \geq 20)$. Different letters indicate significant differences $(\mathrm{P}<0.01)$ (multiple comparison).
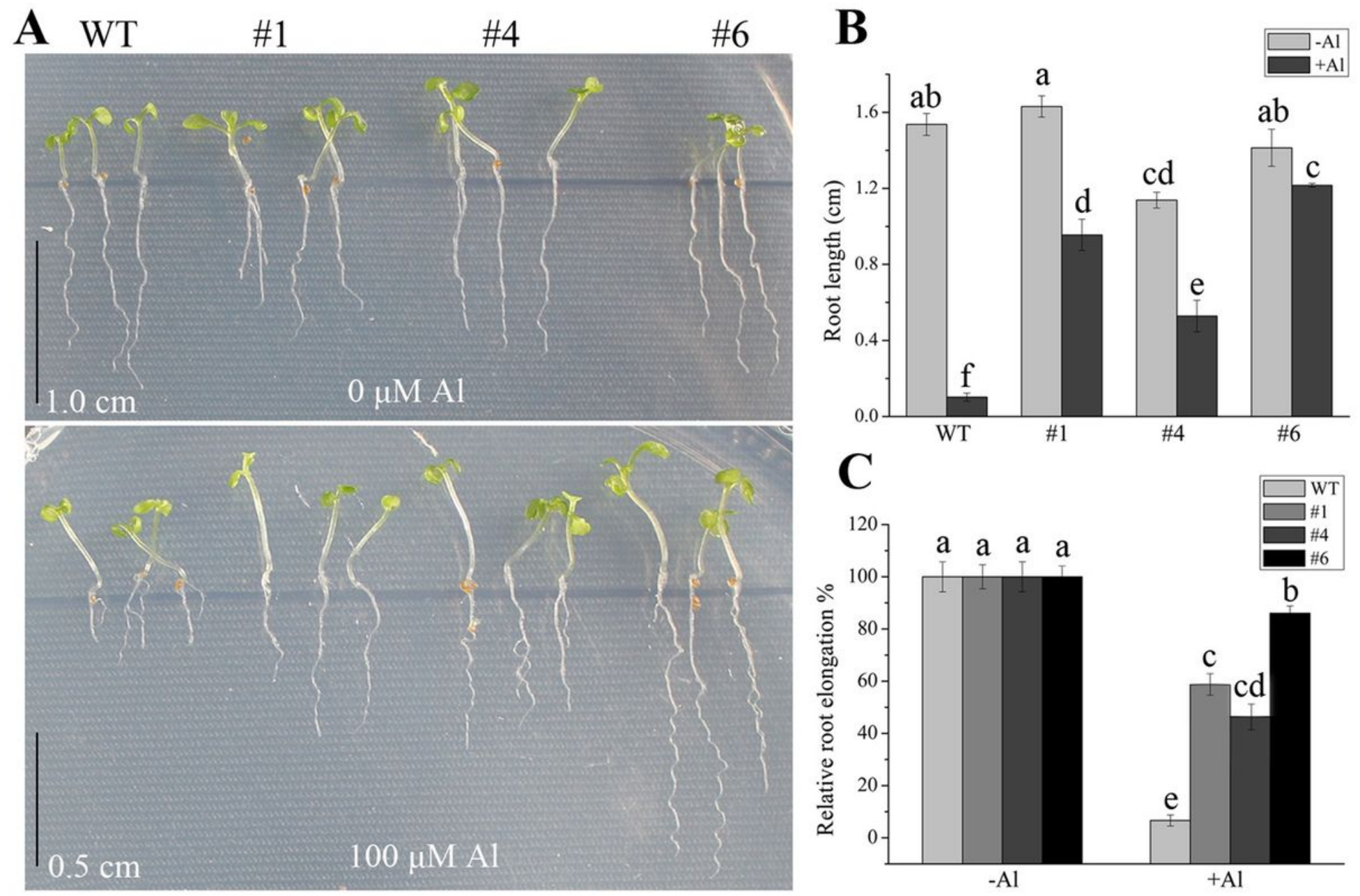

Figure 7 
Transgenic Arabidopsis expressing ZmMATE6 are more Al resistant (A-C) Phenotype of plants (A), root length (B) and relative root elongation (C). Seedlings of wild type Arabidopsis and transgenic lines (\#1, \#4 and \#6) were grown on a plate containing 0 or $100 \mu \mathrm{M}$ AICl3. Scale bar: $1.0 \mathrm{~cm}$. Values represent mean $\pm \operatorname{SD}(n \geq 3)$. Different letters indicate significant differences $(\mathrm{P}<0.01)$ (multiple comparison).

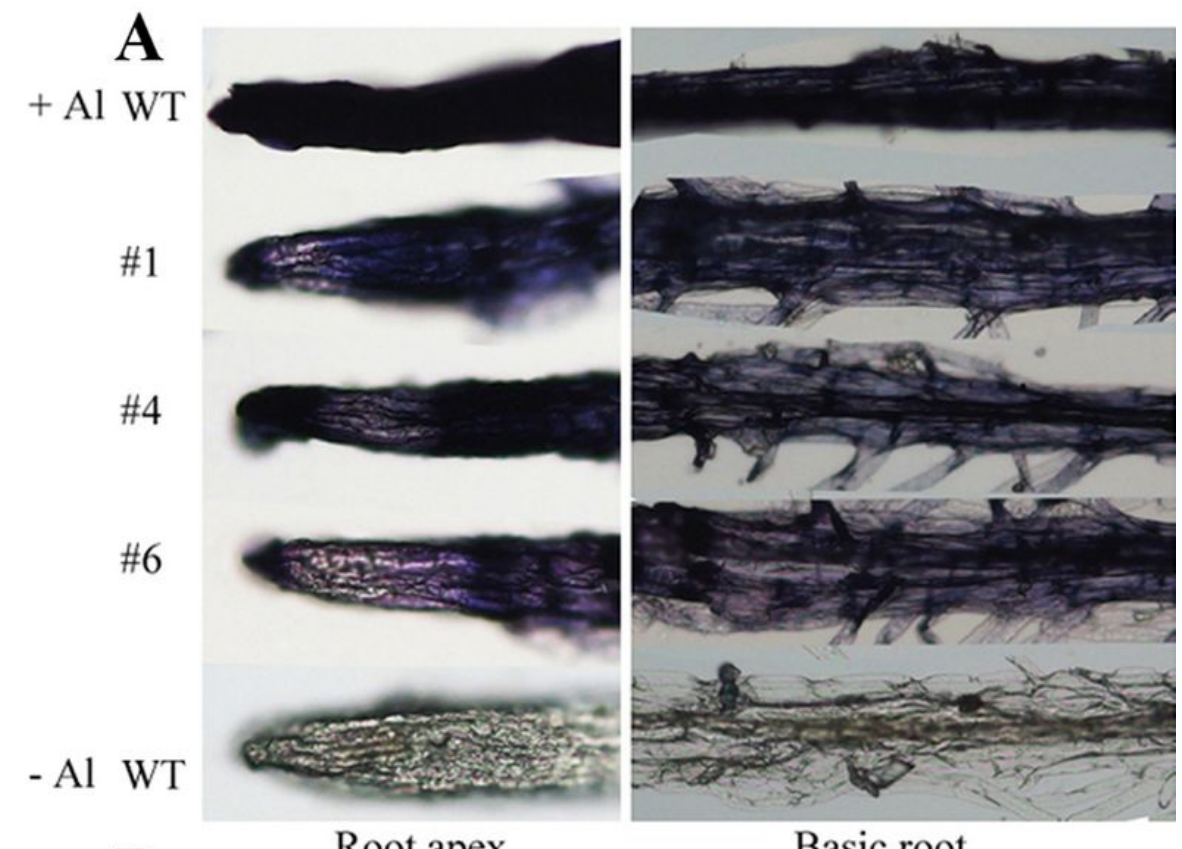
B
Root apex
Basic root

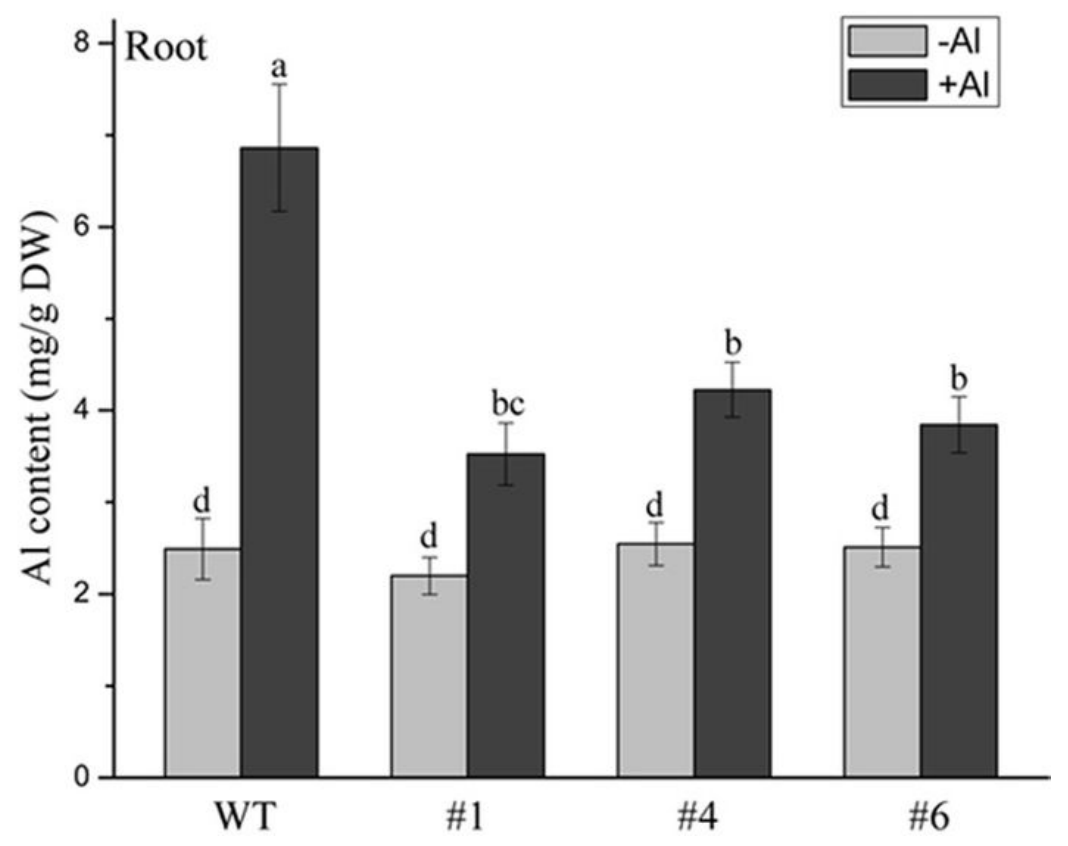

\section{Figure 8}

Overexpression of ZmMATE6 reduces Al accumulation in roots (A) Hematoxylin staining after $12 \mathrm{~h}$ exposure to 0 and 60 $\mu \mathrm{M} \mathrm{AICl} 3$ in roots of the transgenic lines overexpressing ZmMATE6 and WT plants. (B) Al contents of lines (as in (A)) under Al stress for $12 \mathrm{~h}$. Values represent mean \pm SD $(n \geq 10)$. Different letters indicate significant differences $(P<0.01)$ (multiple comparison).

\section{Supplementary Files}


This is a list of supplementary files associated with this preprint. Click to download.

- Fig.S1.tif

- Fig.S2.tif

- Fig.S3.tif

- Fig.S4.tif

- Fig.S5.tif

- Tables1.docx

- TableS2.docx 